\title{
Road Surface Condition and Monitoring System Utilizing Motorcycle (ROCOM)-System Development, Validation and Field Test
}

\author{
Muhammad Marizwan Abdul Manan Muhammad Ruhaizat Abd Ghani \\ Road Safety Engineering and Environment Research Centre, Malaysian Institute of Road Safety Research (MIROS), Lot 125-135, \\ Jalan TKS 1, Taman Kajang Sentral, Kajang, Selangor, Malaysia
}

\begin{abstract}
Motorcycles are the riskiest mode of travel in Malaysia, however motorcycles are also very sensitive to the road surface condition. Thus, by taking advantage of this, a system of software applications that analyses motorcycle motion and mapped out risky road sections was developed, i.e. ROCOM. The system consists of three major components, i.e. ROCOM Data Logger app, which utilizes a smart phone to collect acceleration data, ROCOM Risk Mapping app, which is a web-based application, and ROCOM Visual Tracking, which is a stand along software. ROCOM is able to detect adverse acceleration (> $2 \mathrm{~g}$ ) or vibration on the road surface similar to the High Accuracy GPS Data Logging for Vehicle Testing (VBOX). Risk mapping validation along a section of the motorcycle lane along Federal Route 2 shows that not only ROCOM have the similar risk-mapping pattern, but its route tracking capability on the map is far superior that the VBOX. The pilot and field test results showed that ROCOM works best when mounting the smartphone on the motorcycle handle bar or basket, and it can detect various road anomalies with successful detection rate of $62 \%$, with high detection rate when passing through uneven road surfaces.
\end{abstract}

Key words: Road surface condition, mobile and web-based application, visual tracking, data validation

\section{Introduction}

According to the World Health Organization (WHO), almost to a quarter (24.1\%) of the world's road traffic deaths occur among riders of powered-two-wheelers (PTW) [1], or commonly identified in Asian region as motorcycle [2]. Of these motorcycle fatalities, the South-East Asia region (i.e. mostly low- to middle-income countries) has the highest rate of $49.9 \%$, compared to only up to $10.9 \%$ motorcyclist fatalities in high-income countries in the European region. Malaysia is a good example to study motorcycle safety, as it typifies the countries with safety problems for motorcyclists and in Malaysia, the risk of a motorcycle rider of being fatally injured about 3 times higher than

Corresponding author: Muhammad Marizwan, Ph.D. in engineering, M.Sc. in highway and transportation, B.Sc. in engineering; research field: motorcycle safety. E-mail: mmarizwan@gmail.com,marizwan@miros.gov.my. the risk of a car driver, 6 times higher than pedestrian and nearly 50 times higher than of a bus passenger [3].

One of the contributing factors to PTW crashes is the condition of the road surface. Road surface anomalies, such as potholes, speed bumps, railroad crossings, joints, can cause problems for passing vehicles and can affect road users safety [4]. Road defects such as rutting, water ponding, potholes, corrugation, etc. affect the safety of motorcycles [5-8]. In Malaysia, motorcycle single-vehicle fatal crashes are almost four times more likely than those motorcycle involve in multi vehicle fatal crashes to occur on road with rutting and corrugation[2].

To ensure that roads are free from defects, road maintenance activities have to be done systematically and cost-effectively by the road authorities. Municipalities around the world spend millions of dollars to maintain and repair their roadways [9], thus road quality assessment plays a key role in optimizing 
infrastructure management and road maintenance operations [4]. At the same time, informing drivers on road real conditions, in terms of the presence of bumps, potholes, or other anomalies, has a great importance in order to make the transportation system more safe, efficient and comfortable. In addition, informing drivers of hazardous road conditions [4]especially at night or when lighting is poor would be a useful for motorcyclists.

In the last few years, mobile sensors and computing systems have been developed to collect data on road quality with the final aim of giving real-time information to road users [4]. The monitoring of road conditions can be done by means of several sensors embedded in the mobile devices and nowadays, most of these smartphones/tablets use a three-axis accelerometer to collect acceleration data due to their motion on road anomalies and a GPS receiver to obtain location information of the road segment in question [4, 10]. In this way, each event can be located allowing to create a database of road anomalies by means of a central server to which data can be collected by road users, e.g. such as motorcyclists [11].

Motorcycles are the riskiest mode of travel but on the flip side, it is very sensitive to the road surface condition. Thus, by taking advantage of this characteristic, we aim to develop a system of software applications that analyses motorcycle motion and mapped out risky road sections for motorcyclists.

\section{Literature Review}

Applications for road surface defect detection are not something new. These intelligent transportation system (ITS) technologies have been well documented by Vittorio, et al. [10], Vittorio, et al. [4], Eriksson, et al. [9] and Alessandroni, et al. [12]. This ITS tech are beneficial to drivers navigation system when informing of hazardous road conditions especially at night or when lighting is poor [12]. However, these current developed ITS devices for road defect detection; services and applications are usually designed for four-wheeled vehicles [13] and rarely for motorcycles.

Earlier studies, Vittorio, et al. [10], Vittorio, et al. [4] and Eriksson, et al. [9], used accelerometer sensors on the phone purely to detect extreme values ( $\mathrm{x}, \mathrm{y}$ and $\mathrm{z}$ axis $g$ values) during vehicle movement over road anomalies and they compared those to a normal driving conditions along a well-maintained road. The outcome of this technology would help road authorities to map the information of road defects efficiently as proven successfully by Alessandroni, et al. [12]. This tech however are design for cars, while motorcycles are still at risk without this similar ITS tech.

As explained by Vittorio, et al. [4], the accelerometer is a sensor that can detect linear accelerations along 1, 2 or 3 axes, by measuring the inertial forces, which can be represented with a 3- dimensional Cartesian frame with fixed $x^{\prime} y^{\prime} z$ ', embedded in the mobile device. The accelerometer provides acceleration values in three directions: longitudinal $\left(\mathrm{a}_{\mathrm{x}}\right)$, lateral $\left(\mathrm{a}_{\mathrm{y}}\right)$ and vertical $\left(\mathrm{a}_{\mathrm{z}}\right)$. When the vehicle is in a stationary condition, the only acceleration registered is along the $\mathrm{z}$ axis, and it is equal to gravity:

$$
a_{x}=0 \mathrm{~m} / \mathrm{s}^{2} ; a_{y}=0 \mathrm{~m} / \mathrm{s}^{2} ; a_{z}=9.81 \mathrm{~m} / \mathrm{s}^{2}=1 \mathrm{~g}
$$

Previous studies such as in Vittorio, et al. [4], Kitani [13] and González, et al. [14], relied on the orientation of the accelerometer sensors so that the $\mathrm{x}$ axis identified the longitudinal direction, the $\mathrm{y}$ axis the transversal one and the $\mathrm{z}$ axis the perpendicular direction to the xy plane.

\section{Method}

This research project requires the team to develop a system of application, which comprise of a mobile, a web-based application and a stand-alone software. After the development of ROCOM, data validation and field test was carried out in order to test and evaluate the system. Once the system has been developed, the system undergoes data validation and field test.

\subsection{System Development}

Conceptually, a mobile app (ROCOM Data Logger) 
in the smartphone records the acceleration of the motorcycle's motion and video of the ride-through. The acceleration data is transferred via Internet into a web-based application (ROCOM Risk Mapping) for risk mapping, while the video data is transferred into a stand-alone software (ROCOM Visual Tracking) for visual tracking analysis (see Fig. 1).The development of video tracking capability requires us to integrate the smart phone's camera function with the GPS and built-in map software. This capability was suited as a stand along software components of the system.

\subsection{Data Validation}

The data validation was carried out utilizing the High Accuracy GPS Data Logging for Vehicle Testing (VBOX) as the baseline equipment. The location of the field test was along a section of the exclusive motorcycle lane along the Federal Highway (FR2). The data validation is based on two areas, i.e. risk mapping validation and acceleration data validation.

\subsection{Pilot and Field Test}

Before the field-test being conducted, a pilot tests were conducted on $15^{\text {th }}$ November 2016 (9.30 am), in the city of Kajang in the Kajang district (see Fig. 5). The objective of the pilot test was to test the capability of ROCOM to detect the road defects depending on the way of mounting the device on the motorcycle. The way of mounting of the phone on the motorcycle were as follow:

I. On the handle bars

II. In the motorcycle basket

III. In the rider's backpack

This test requires us to control the road environment (based on the selected sites) and also the rider. Thus, the pilot test employed two selected riders with good riding fitness and experience and also two well-maintained motorcycles. During the tests, they were required pass along the test route, which consisted of various road defects objects demanding abrupt braking and weaving.

The field tests were conducted on the $25^{\text {th }}$ November 2016 (9.00 am) at Jalan Seksyen 2/15, Kajang Utama, Kajang, Selangor. The objective of the tests was to test the capability of ROCOM to obtain the acceleration values for each object of interest. Fifteen qualified riders passed through a $400 \mathrm{~m}$ test route containing eight obstacles with their motorcycles equipped with a mobile smartphone.

To obtain variations in the data collected the type of riders and motorcycles were varied. The riders were not familiar with the test route. This was in order to maintain the Naturalistic riding behaviour - the riders to perform the test rides with their usual riding behaviour without anticipating the obstacles ahead.

The tests required us to control the road environment the best possible by fixing the road environment and road obstacles. The eight obstacles along the test route

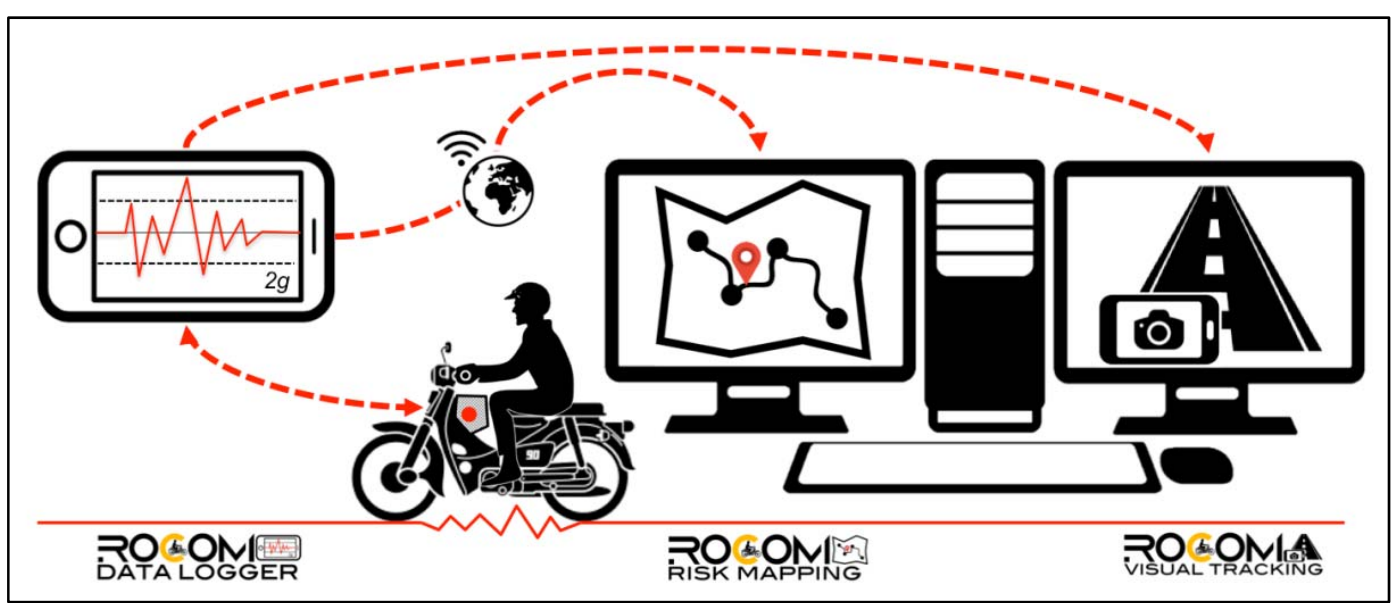

Fig. 1 Schematic diagram of ROCOM. 
were as follows: 1) weaving area, 2) road hump number 1,3 ) uneven surface number 1,4 ) abrupt braking area, 5) road hump number 2,6 ) uneven surface number 2,7 ) road hump number 3 , and 8 ) pothole (see Fig. 2). The riders were told to pass through obstacle 1, 2 and 3 without stopping until obstacle 4 , where they had to perform an abrupt breaking and then proceed to the rest of the obstacles until reaching the end of the test route.

\section{Results}

The subsection below shows the results of the developed applications, field test and data validation results.

\subsection{ROCOM Data Logger}

The mobile application software development was done using Apple's IOS system software. The ROCOM Data logger app developed and designed in such way that that the rider would not need to have the smart phone to be in exact orientation of $\mathrm{x}, \mathrm{y}$ and $\mathrm{z}$, i.e. in order to detect high or extreme acceleration or g-force with respect to the road defects or anomalies. Instead, In other words, the motorcyclists would just mount the phone on the motorcycle (e.g. on the handle bars or place securely in the basket) in any position.

In principle, the app would detect and record a vertical acceleration when passing a bump, or an undulating road section, or a horizontal acceleration when abruptly weaving past a pothole or object. For the high or extreme acceleration, we have set the ROCOM minimum threshold of $2 \mathrm{~g}$, which is equivalent to 19.62 $\mathrm{m} / \mathrm{s}^{2}$. This threshold is based on previous findings such as in eCall and Wreck Watch as seen in $[15,16]$.

Our system was designed in such a way that the mobile app would automatically collect the data once it is activated, and at the end of the ride, the data will be saved into a text file, ready to be transferred via email, Bluetooth, cloud, etc.

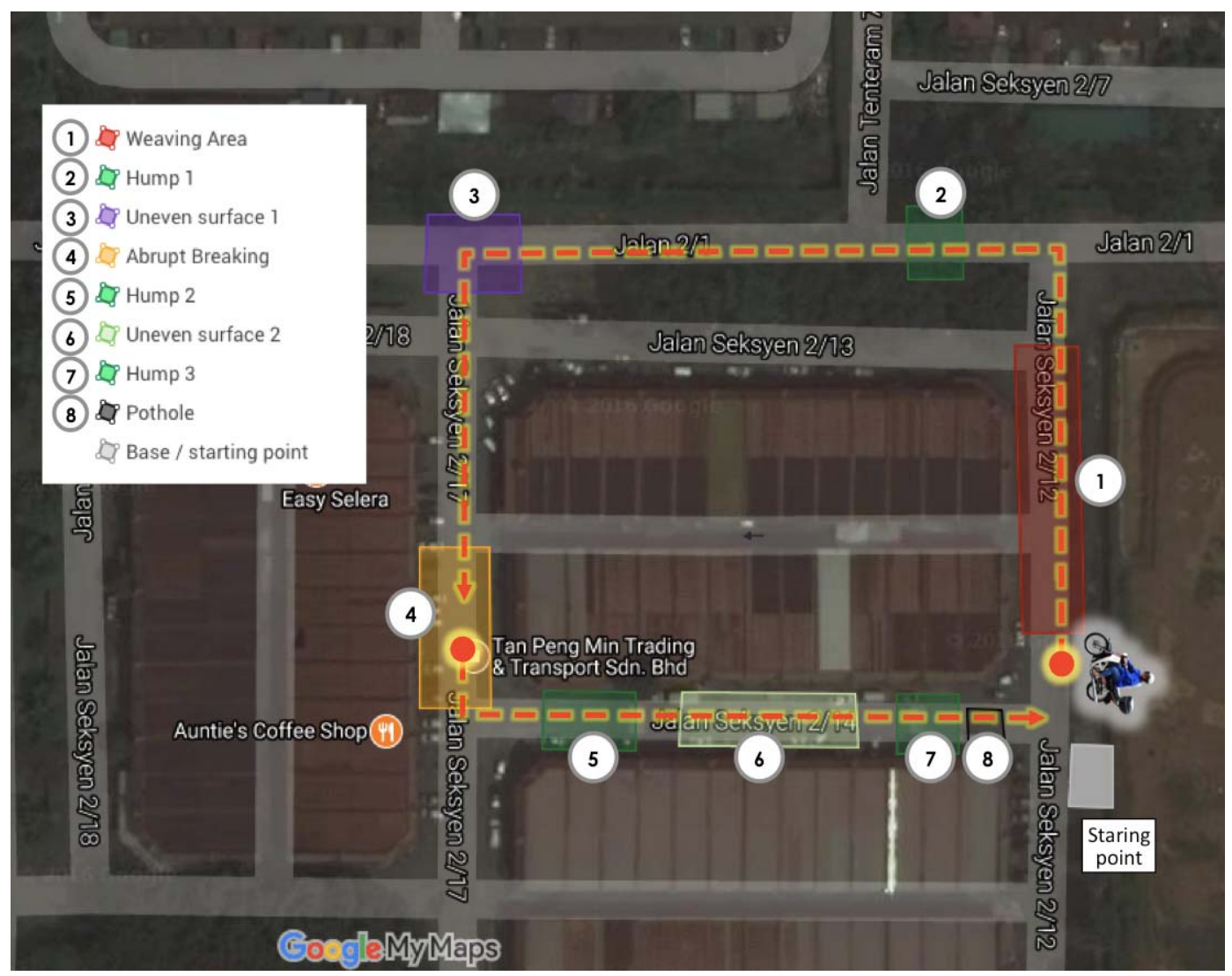

Fig. 2 Field test route of ROCOM. 


\subsection{ROCOM Risk Mapping}

ROCOM Risk Mapping application is a web-based system that was developed as a tool to analyse the data(i.e. acceleration forces) from ROCOM Data Logger and display the location geographically of high threshold acceleration or road anomalies on a dedicated map.

The web base it consists of three interface: Overview, Map and Data display (see Figs. 3 and 4). The Overview interface displays the some details about the rider's travelled distance, his or her average speed, total

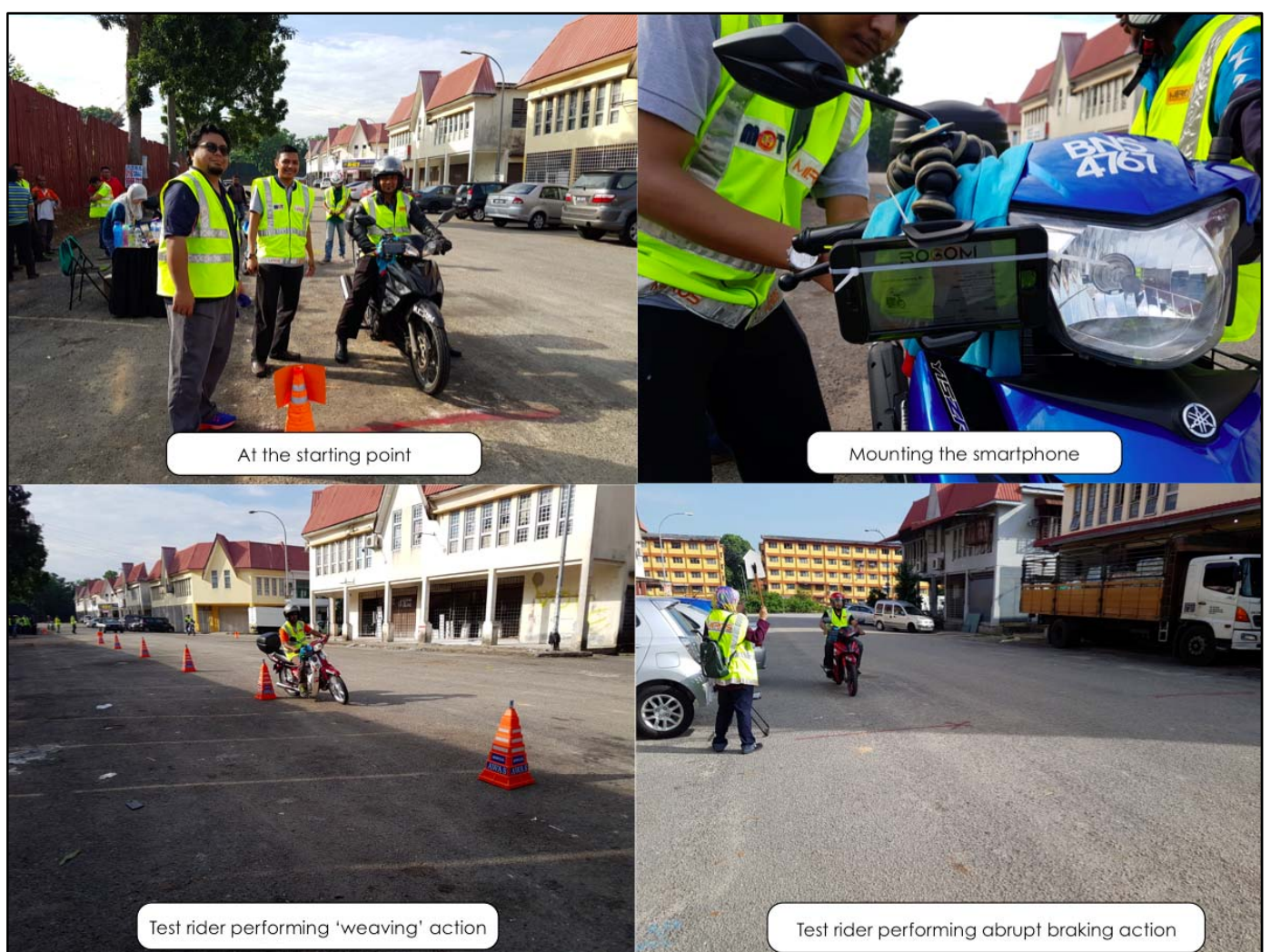

Fig. 3 Photos at field test-obstacle 1 and 4.

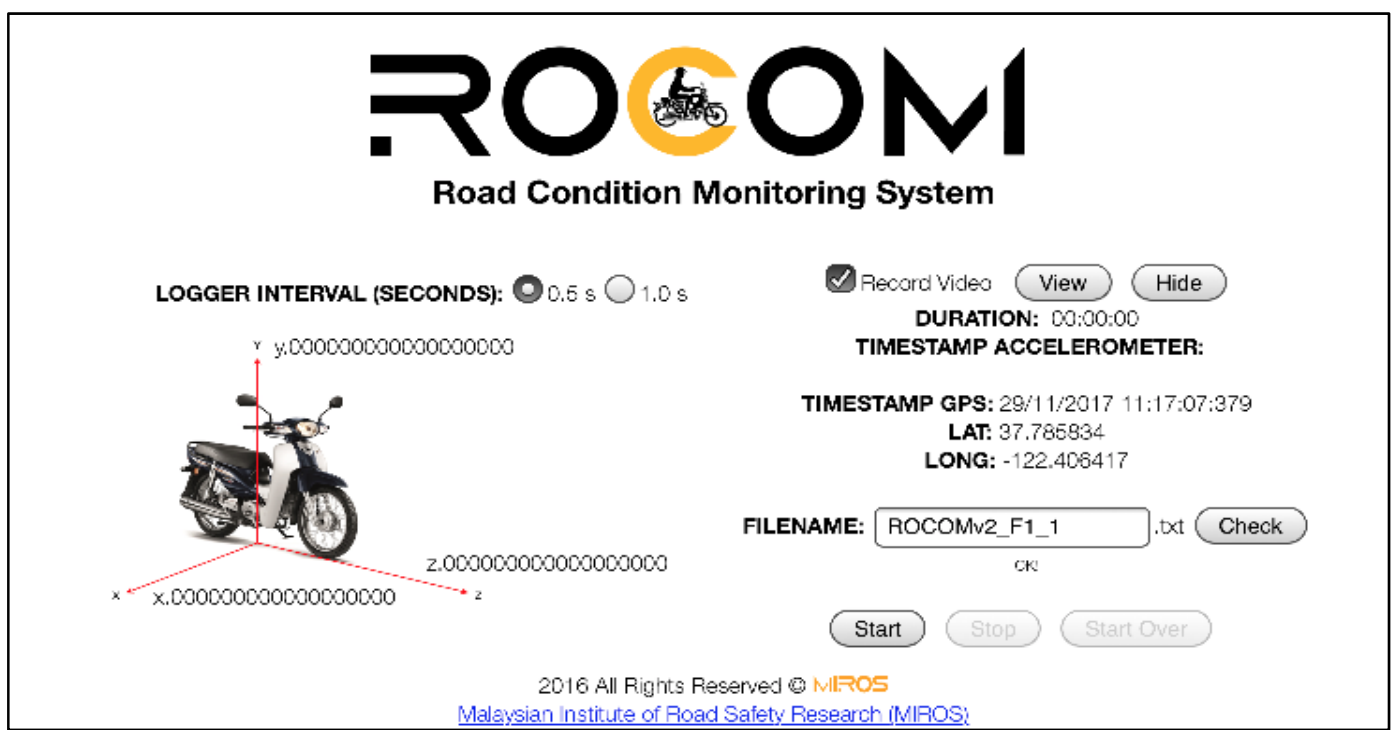

Fig. 4 Screen capture of ROCOM Data Logger app. 
data collected and number of acceleration exceeded the susceptible limit of $2.0 \mathrm{~g}$. The Map interface reveals the risk mapping or the route that the rider has travelled (indicated by the green line) with the location where the occurrence of acceleration exceeded the susceptible limit of 2.0g. Lastly, the Data display section reveals a more detail information in terms of the acceleration figures and graph, and each GPS coordinate with respect to the sequential timestamp on when and where the data was logged by ROCOM.

\subsection{ROCOM Visual Tracking}

Video tracking is one of the value-added functions the ROCOM system. ROCOM Visual Tracking is a software that can be run only in computer with Microsoft Windows. The software runs upon clicking on executable file, where the user needs to choose the raw data (from ROCOM Data Logger) and video file to start the video tracking. The video, maps, and line chart panel will run according to video timestamp and raw data point (see Fig. 6). This software also provides video interaction such as pause and resume, zooming in and out. This video tracking serves best when users wants to view the road surface condition with respect to the high acceleration obtain from ROCOM Data Logger and ROCOM Risk Mapping app.

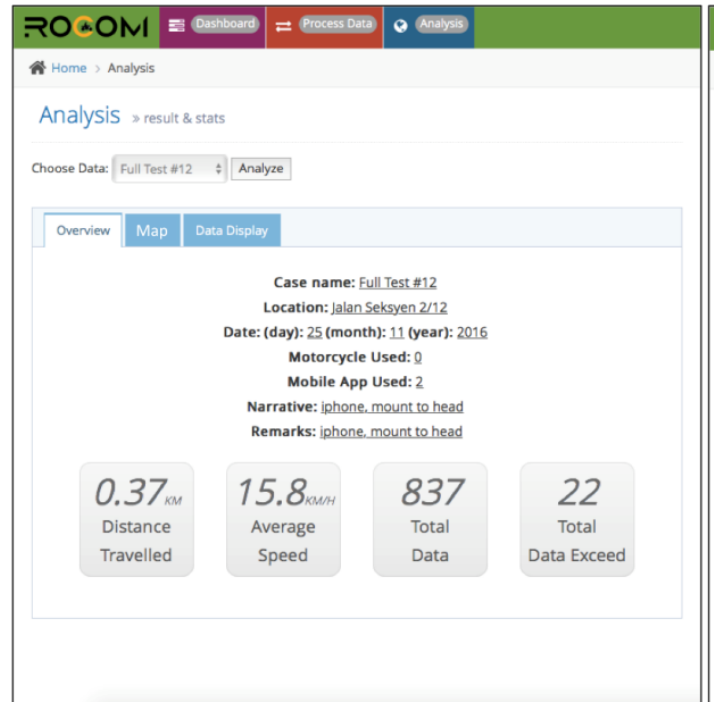

\subsection{Data Validation Result}

Data validation was carried out utilizing the VBOX as the baseline. The location of the field test was along a section of the exclusive motorcycle lane along the Federal Highway (FR2), from the Jalan Templer-Persiaran Narayanan interchange to the LDP interchange. The total distance travel was $6.11 \mathrm{~km}$ with the average speed of travel along the exclusive motorcycle lane of $22.7 \mathrm{~km} / \mathrm{h}$. During the validation, ROCOM and the VBOX was synched and run together for three times along the same road section, same motorcycle and same mounting procedure.

\subsubsection{Acceleration Data Validation}

Validating each and every point from ROCOM and VBOX is a strenuous task. Moreover, not all of the points for each trial run are the same due to the fact that different rider goes on a different path despite the constant type of motorcycle. Thus, we have chosen one location that has similar coordinate for both devices in order to validate the acceleration readings.

Table 1 shows the acceleration data comparison between ROCOM and VBOX. The single data on the same location has shown that all of the $\mathrm{x}$-axis acceleration value for both ROCOM and VBOX exceeded the $19.60 \mathrm{~m} / \mathrm{s}^{2}$ threshold for each trial. The

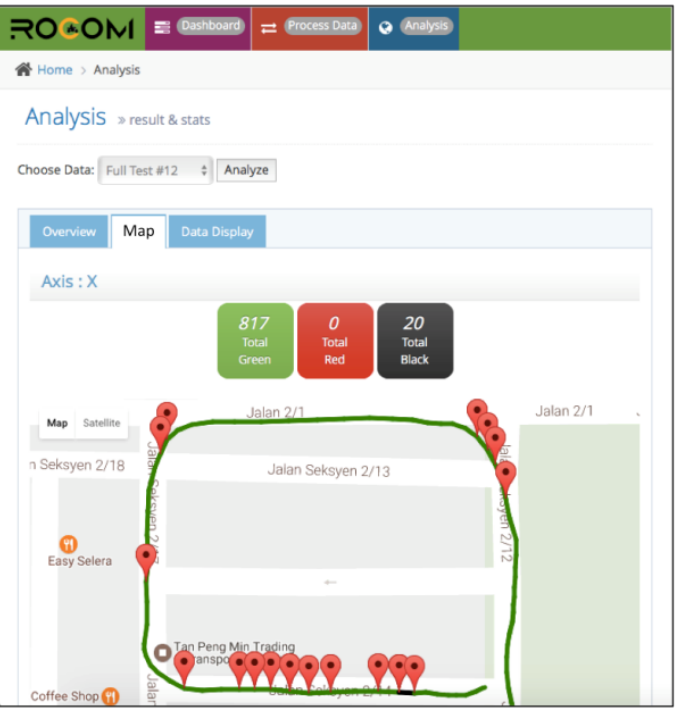

Fig. 5 Screen capture of ROCOM Risk Mapping app. 


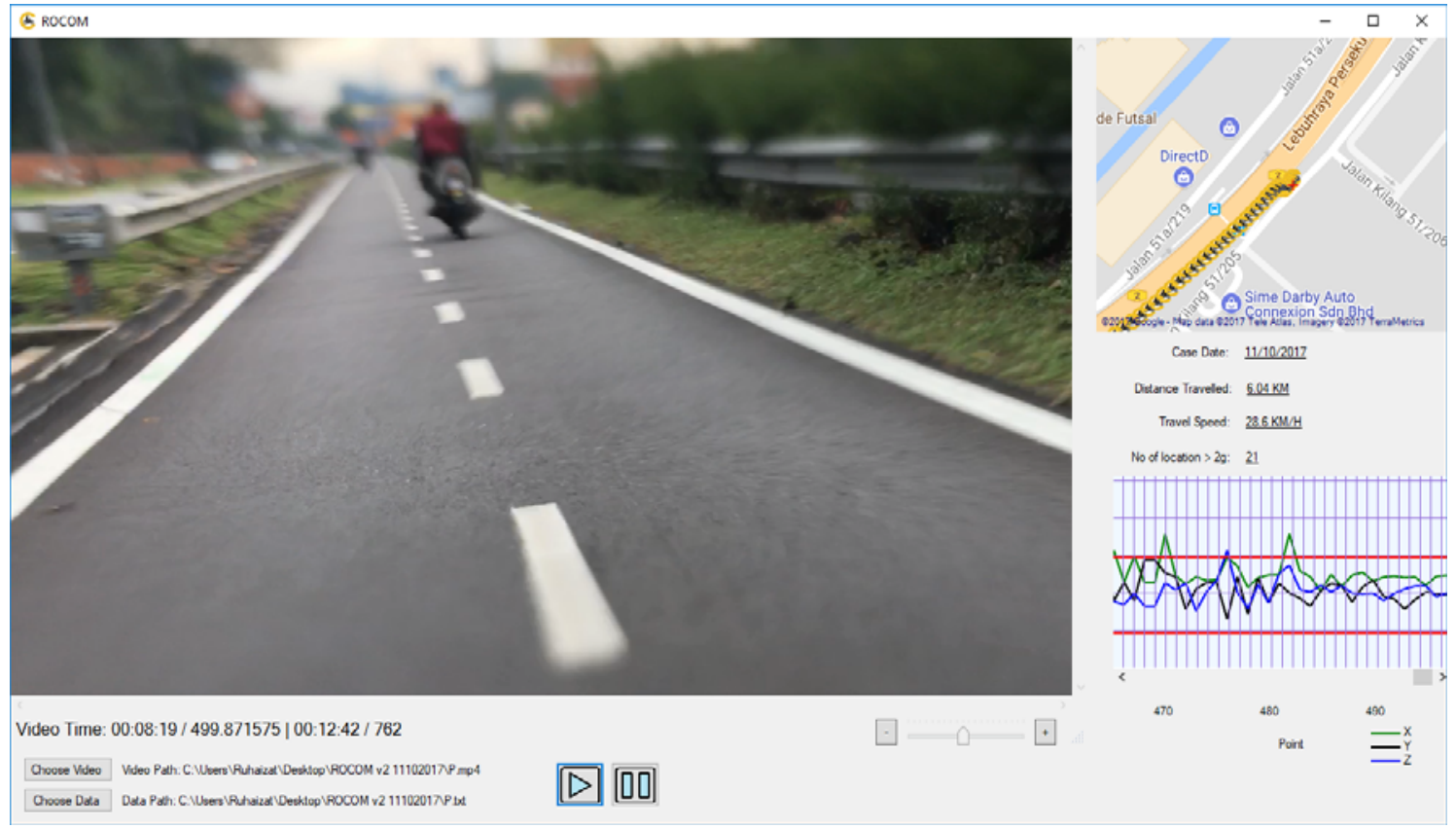

Fig. 6 Screen capture of ROCOM Visual Tracking.

Table 1 Acceleration data validation for ROCOM and VBOX.

\begin{tabular}{|c|c|c|c|c|c|c|}
\hline Trial & \multicolumn{2}{|c|}{1} & \multicolumn{2}{|c|}{2} & \multicolumn{2}{|c|}{3} \\
\hline Latitude & \multicolumn{2}{|c|}{3.0851} & \multicolumn{2}{|c|}{3.0851} & \multicolumn{2}{|c|}{3.0853} \\
\hline Longitude & \multicolumn{2}{|c|}{101.6236} & \multicolumn{2}{|c|}{101.6233} & \multicolumn{2}{|c|}{101.6237} \\
\hline Device & $\# 1 \mathrm{VBOX}$ & \#1 iPhone & \#2 VBOX & \#2 iPhone & \#3 VBOX & \#3 iPhone \\
\hline Acc. on $X\left(\mathrm{~m} / \mathrm{s}^{2}\right)$ & $20.1(2.05)$ & $29.8(3.04)$ & $27.6(2.81)$ & $22.2(2.26)$ & $21.7(2.21)$ & $24.7(2.52)$ \\
\hline Acc. on $Y\left(\mathrm{~m} / \mathrm{s}^{2}\right)$ & $11.9(1.21)$ & $-4.4(-0.45)$ & $-20.7(-2.11)$ & $-10.1(-1.03)$ & $0.8(0.08)$ & $\begin{array}{l}-7.9 \\
(-0.81)\end{array}$ \\
\hline Acc. on $\mathrm{Z}\left(\mathrm{m} / \mathrm{s}^{2}\right)$ & $11.9(1.21)$ & $13.3(1.36)$ & $-20.7(-2.11)$ & $-0.1(-0.01)$ & $0.8(0.08)$ & $5.7(0.58)$ \\
\hline
\end{tabular}

( ): The value in the brackets are the value of the equivalent $g$ value.

Acc. : Acceleration.

The red italic number indicate that the value of the acceleration $\left(\mathrm{m} / \mathrm{s}^{2}\right)$ exceed the $19.62 \mathrm{~m} / \mathrm{s}^{2}$ threshold.

acceleration differences are between $3.0 \mathrm{~m} / \mathrm{s}^{2}$ to 9.7 $\mathrm{m} / \mathrm{s}^{2}$ compared to the VBOX data. This shows that ROCOM is able to detect adverse acceleration or vibration on the road surface similar to VBOX.

\subsubsection{Risk Mapping Validation}

Fig. 7 shows the risk mapping comparison between ROCOM and VBOX for each trial. From the figure, we can see that both ROCOM and VBOX have the similar risk mapping pattern, i.e. most of the red markers are located similarly between trials. However, the VBOX route mapping (the green line) is inferior to the ROCOM, by which the VBOX route does not coincide with the map compared to ROCOM (see ). This may be due to the low accuracy of the standalone VBOX GPS system where else the iPhone has several complementary technologies on board that work in conjunction with the GPS chip to master the phone's location, i.e. accelerometer and gyroscope, Wi-Fi Tracking, compass, Barometer and M10 Motion Coprocessor.

\subsection{Pilot and Field Test Results}

The pilot test results showed that mounting the smartphone on the motorcycle handle bar and fasting it on the motorcycle basket with the ROCOM activated had the highest success rate of detecting the obstacles compared to placing the smartphone in the backpack. 


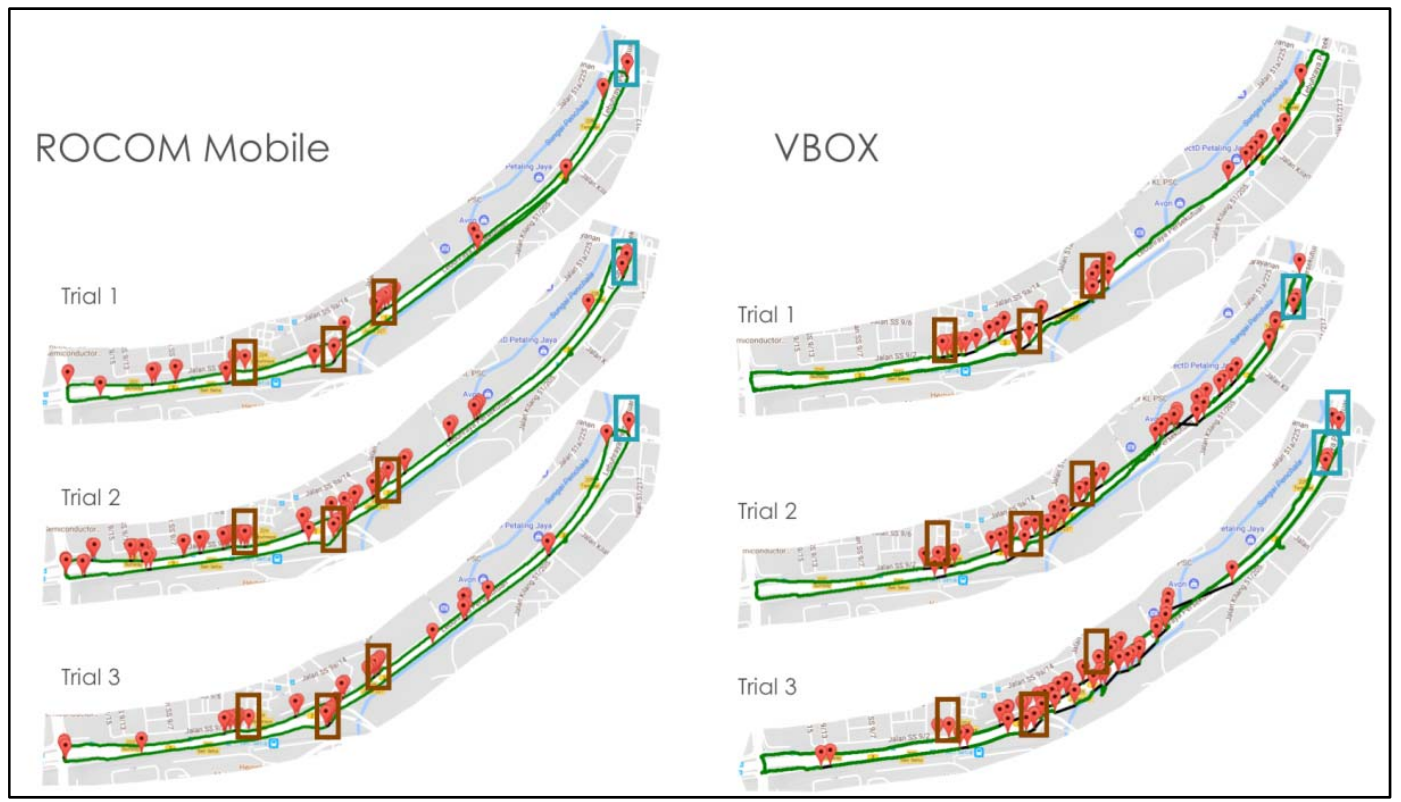

Fig. 7 ROCOM Mobile and VBOX risk mapping comparison for each trial.

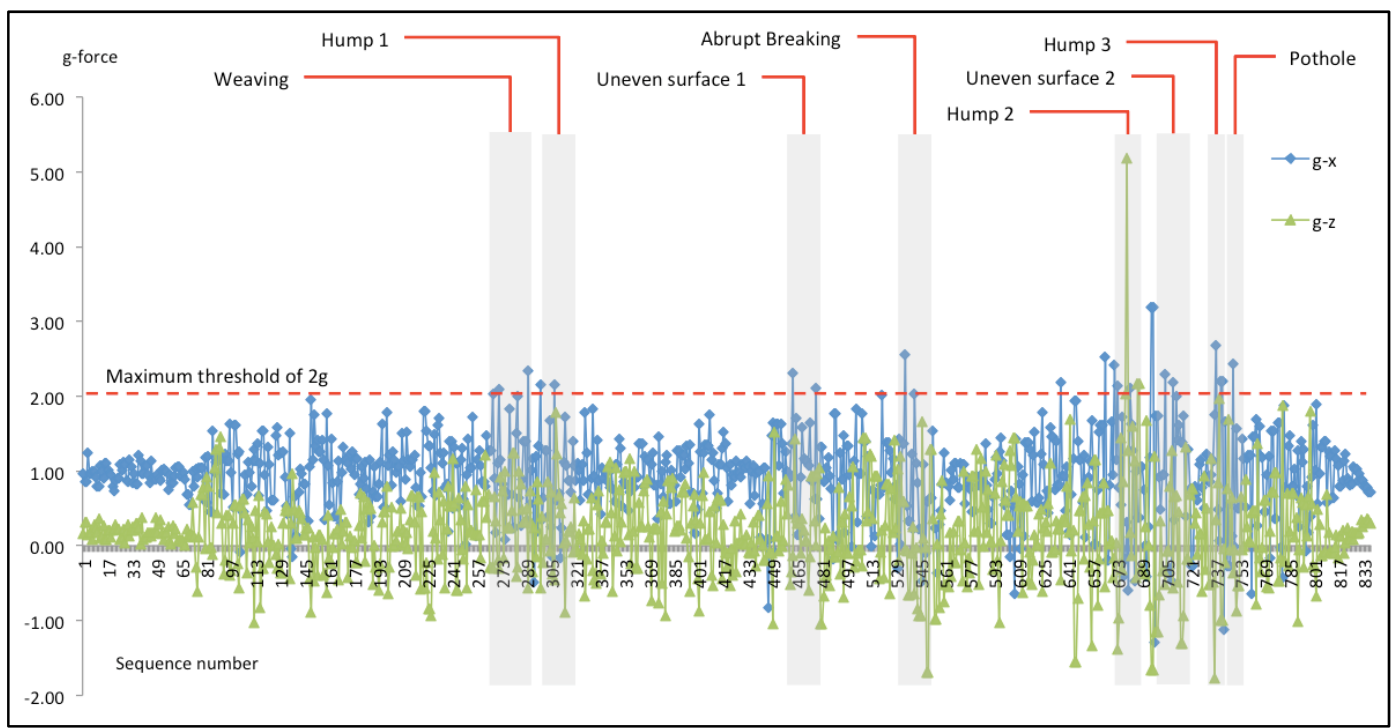

Fig. 8 The acceleration graph matched with the location of the obstacles.

To evaluate the detection capabilities of ROCOM, data of each individual trial was recorded with a frequency of $0.01 \mathrm{~Hz}$ and for each obstacle its acceleration readings were observed and match (see Fig. 7). Those exceeding acceleration readings exceeding $2 \mathrm{~g}$ were counted and compared with other rider.

Results from the field test indicated that ROCOM is able to detect various obstacles with the average of successful detection rate of $\mathbf{6 1 . 9 \%}$ while the highest successful detection rate (80\%) occurred when riders passed through uneven surface and roadhumps.

\section{Discussion and Conclusion}

The aim of the work described in this paper was to develop mobile- and web-based application software that analyses motorcycle motion data gathered from a mobile app and mapped out the hazardous road sections for motorcyclists. We have developed a system that consists of three major components, i.e. ROCOM Data Logger app, which utilizes a smart 
phone to collect acceleration data, ROCOM Risk Mapping app, which is a web-based application, and ROCOM Visual Tracking, which is a stand along software.

The results from our data validation and field test show that ROCOM has similar capabilities as software developed by Kitani, et al. [17], Vittorio, et al. [10] and Eriksson, et al. [9], that could record road surface condition and map out the risky location. The study also finds that ROCOM Visual Tracking app was able to proof the accuracy of road surface detection from raw data taken by ROCOM Data Logger. While the ROCOM Risk Mapping application shows that not only ROCOM have the similar risk-mapping pattern with the High Accuracy GPS Data Logging for Vehicle Testing (VBOX), but its route tracking capability on the map is far superior that the VBOX.

The pilot and field test results showed that ROCOM works best when mounting the smartphone on the motorcycle handle bar or basket, and it can detect various road anomalies with successful detection rate of $62 \%$, with high detection rate when passing through uneven road surfaces.

Further tests and calibrations of ROCOM are needed in terms of finding the ideal condition (e.g. appropriate speed) for accurate detection. Although we have found that mounting on the handlebars is suitable for a better detection rate, the mounting equipment must be placed so that it is close to the handed in order to mitigate the effects of vibrations. Thus, we recommend that ROCOM should have custom made mounting equipment.

\section{Acknowledgments}

The authors would like to express their appreciation to the Director of Road Safety Engineering and Environment Research Centre, Dr Siti Zaharah Ishak for giving permission to conduct this project and extending their support to produce this report. The authors would also like to express special thanks to the team members and research assistants Siti Nurhidayah
Binti Musa, Azzemi Bin Aziz, Mohd Saifullah Bin Mohd Sohi, Zulfadhli Bin Sharifudin, Norhazlina Binti Razali, and Muhammad Ridzuan Bin Basah for their help and contribution in completing the project.

\section{References}

[1] WHO. 2013. Global Status Report on Road Safety 2013: Supporting a Decade of Action. World Health Organization, Geneva, Switzerland.

[2] Abdul Manan, M. M., Várhelyi, A., Çelik, A. K., and Hashim, H. H. 2017. "Road Characteristics and Environment Factors Associated with Motorcycle Fatal Crashes in Malaysia.” IATSS Research.

[3] Abdul Manan, M. M., and Várhelyi, A. 2012. "Motorcycle Fatalities in Malaysia.” IATSS Research 36 (1): 30-9.

[4] Vittorio, A., Caruso, M. V., Danieli, G., Festa, D. C., Giofrè, V. P., Iuele, T., and Vaiana, R. 2012. "A Mobile Application for Road Surface Quality Control: UNIquALroad." Procedia-Social and Behavioral Sciences 54: 1135-44.

[5] Elliott, M. A., Baughan, C. J., Broughton, J., Chinn, B., Grayson, G. B., Knowles, J., Smith, L. R., and Simpson, H. 2003. "Motorcycle Safety: A Scoping Study." TRL Report TRL 581, TRL, UK.

[6] Haque, M. M., Chin, H. C., and Huang, H. 2009. "Modeling Fault among Motorcyclists Involved in Crashes.” Accident Analysis \& Prevention 41 (2): 327-35.

[7] Haworth, N. 2012. "Powered Two Wheelers in a Changing World, Challenges and Opportunities." Accident Analysis \& Prevention 44 (1): 12-8.

[8] Forkenbrock, G., Hoover, R. L., Gerdus, E., Buskirk, T. R. V., and Heitz, M. 2014. "Blind Spot Monitoring in Light Vehicles-System Performance.” National Highway Traffic Safety Administration, Washington, DC,Report No. DOT HS 812045.

[9] Eriksson, J., Girod, L., Hull, B., Newton, R., Madden, S., and Balakrishnan, H. 2008. "The Pothole Patrol: Using a Mobile Sensor Network for Road Surface Monitoring.” In MobiSys'08, Breckenridge, Colorado, USA.

[10] Vittorio, A., Rosolino, V., Teresa, I., Vittoria, C. M., Vincenzo, P. G., and Francesco, D. M. 2014. “Automated Sensing System for Monitoring of Road Surface Quality by Mobile Devices.” Procedia-Social and Behavioral Sciences 111: 242-51.

[11] Lee, U., and Gerla, M. 2010. "A Survey of Urban Vehicular Sensing Platforms.” Computer Networks 54 (4): 527-44.

[12] Alessandroni, G., Klopfenstein, L. C., Delpriori, S., Dromedari, M., Luchetti, G., Paolini, B. D., Seraghiti, A., Lattanzi, E., Freschi, V., Carini, A., and Bogliolo, A. 2014. 

Development, Validation and Field Test

"Smart Road Sense: Collaborative Road Surface Condition Monitoring." in UBICOMM 2014 : The Eighth International Conference on Mobile Ubiquitous Computing, Systems, Services and Technologies.

[13] Kitani, T. 2013. "A Prototype of a Vehicle-Motion Sensing System with a Smartphone and Dedicated Sensing Devices.” In Bicycle and Motorcycle Dynamics 2013: Symposium on the Dynamics and Control of Single Track Vehicles, Narashino, Japan.

[14] González, A., O'Brien, E. J., Li, Y. Y., and Cashell, K. 2008. "The Use of Vehicle Acceleration Measurements to Estimate Road Roughness.” Vehicle System Dynamics 46 (6): 483-99.
[15] Bliss, T., and Breen, J. 2009. Country Guidelines for the Conduct of Road Safety Management Capacity Reviews and the Specification of Lead Agency Reforms, Investment Strategies and Safe System Projects. Washington DC: The World Bank Global Road Safety Facility.

[16] Linins, A., and Berjoza, D. 2010. "Experimental Investigation in Acceleration of Vehicles.” In Engineering for Rural Development, Jelgava.

[17] Kitani, T., Miyazawa, A., Kamimura, T., Shiomi, A., and Watanabe, T. 2012. “A Motion Sensing System to Grasp a Motorcycle's Behavior with Sensors as Mounted on a Smartphone.” In International Workshop on Informatics (IWIN2012), 115-20. 